\title{
Division Method and Seepage Law of Seepage Channels in a Tight Reservoir
}

\author{
Zhenkai Wu $\mathbb{D},{ }^{1,2}$ Feifei Fang $\left(\mathbb{D},{ }^{3}\right.$ Xizhe Li $\mathbb{D},{ }^{1,2,4}$ Hanmin Xiao, ${ }^{1,2,4}$ Xuewei Liu, ${ }^{2,4}$ \\ Yuan Rao ${ }^{D},{ }^{1,2}$ Yang $\mathrm{Li}^{4}$ Jie Wang, ${ }^{3}$ Yongcheng Luo, ${ }^{1,2}$ and ${\mathrm{Zhi} \mathrm{Li}^{5}}^{5}$ \\ ${ }^{1}$ School of Engineering Science, University of Chinese Academy of Sciences, Beijing 100049, China \\ ${ }^{2}$ Institute of Porous Flow and Fluid Mechanics, University of Chinese Academy of Sciences, Langfang 065007, China \\ ${ }^{3}$ School of Petroleum Engineering, Chongqing University of Science and Technology, Chongqing 401331, China \\ ${ }^{4}$ Research Institute of Petroleum Exploration \& Development, Beijing 100083, China \\ ${ }^{5}$ Exploration and Development Research Institute of Sinopec Zhongyuan Oilfield Company, Puyang City, \\ Henan Province 457000, China
}

Correspondence should be addressed to Feifei Fang; fangfeifei@cqust.edu.cn and Xizhe Li; 1xz69@petrochina.com.cn

Received 21 July 2021; Revised 19 August 2021; Accepted 4 September 2021; Published 29 October 2021

Academic Editor: Xiaofei Sun

Copyright (C) 2021 Zhenkai Wu et al. This is an open access article distributed under the Creative Commons Attribution License, which permits unrestricted use, distribution, and reproduction in any medium, provided the original work is properly cited.

Tight oil reservoirs are characterized by a low porosity, low permeability, and strong heterogeneity. The macropores, throats, and microcracks in reservoirs are the main seepage channels, which affect the seepage law in the reservoirs. In particular, oil-water two-phase flow in different types of pores requires further study. In this study, two groups of online NMR displacement experiments were designed to study the seepage characteristics of tight oil reservoirs. It was found that the main seepage channels for oil-water two-phase flow are the microcracks, large pores, and throats in the reservoir. The large pores are mainly micron and submicron scale in size. The oil in the small pores is only transferred to the large pores through imbibition to participate in the flow, and there is no two-phase flow. Based on the influence of different pore structures on the seepage law of a tight reservoir, the pores were divided into seepage zones, and a multistage seepage model for tight reservoirs was established. Based on this model, the effects of the imbibition, stress sensitivity, threshold pressure gradient, and Jamin effect on model's yield were studied. The results show that imbibition is no longer effective after a while. Owing to the stress sensitivity, the threshold pressure gradient, and the Jamin effect, oil production will be reduced. As the parameter value increases, the oil production decreases. The production decreases rapidly in the early stage of mining while decreases slowly in the later stage, exhibiting a trend of high yield in the early stage and stable yield in the later stage.

\section{Introduction}

With the development of the petroleum industry, conventional oil and gas resources are gradually being depleted, and the recoverable amount of unconventional oil and gas resources is gradually increasing [1]. In particular, since the twenty-first century, the successful exploitation of shale gas in the United States has stimulated the exploration of unconventional oil and gas resources in countries around the world $[2,3]$. Among them, tight oil reserves are abundant, and tight oil has developed into one of the important alternative energy sources for conventional oil. Therefore, the study of tight oil reservoirs has become a hot research topic, and the seepage channels and seepage laws of tight reservoirs have become necessary factors for understanding tight reservoirs. Numerous scholars have found that microcracks are widely developed in tight oil reservoirs. When microcracks appear in the matrix, the seepage capacity of the reservoir is greatly improved [4-6]. Microcracks refer to cracks with widths of less than $10 \mu \mathrm{m}$ and aspect ratios of greater than 10 [7]. Owing to the low porosity and low permeability characteristics of tight reservoirs, the capillary force also plays an important role in the fluid flow process and is a nonnegligible factor influencing seepage. At present, 
the definition of the capillary force in oil and gas reservoirs is relatively uniform. When two immiscible fluids flow in a capillary, one phase is usually dispersed in the other phase as a plunger. The fluid forms many crescent-shaped interfaces in the region of two-phase flow, and the pressure on both sides of the interface is not equal. The pressure difference is defined as the capillary force [8]. Therefore, it is of great significance to study the seepage law under the influence of microcracks and the capillary force in tight oil reservoirs.

The microcracks and capillary force are two key factors that affect the effective development of reservoirs. Microcracks are the main seepage channels in tight reservoirs [9, 10], which are driven by the production pressure difference. They can directly transport oil into the large fractures, which has a continuous impact on the productivity of the oil wells and can increase production. However, as reservoir's permeability increases, this promotion effect will slow down [11, 12]. The capillary force is mainly manifested as imbibition and the Jamin effect in tight oil reservoirs. In imbibition, the capillary force acts as a local motive force to replace the oil that cannot be controlled by the microcracks and pores. In the Jamin effect, the capillary force acts as a seepage resistance and increases the difficulty of tight oil recovery [13-16]. Based on this, many experts and scholars have studied the seepage law of tight oil reservoirs under the influence of microcracks. Hu et al. [17] proposed a semianalytical model for predicting the two-phase productivity of cracked horizontal wells. In their model, the effects of the microcracks and capillary force were considered. They found that microcracks can improve reservoir's permeability and lead to a substantial increase in production. In their model, capillary pressure is beneficial to oil production. The dynamic capillary pressure caused by water saturation is always less than the static capillary pressure, and the dynamic effect is only obvious in the initial production stage. Zhu et al. [5] studied the microcrack characteristics of the tight sandstone in the Ordos Basin. Their results revealed that the existence of microcracks greatly increases the permeability of the reservoir and enhances the heterogeneity of the reservoir. The pressure curve obtained from mercury injection experiments is significantly affected. Therefore, a quantitative microcrack identification standard was established based on the capillary pressure curve. Li et al. [18] studied the microseepage and crack effectiveness of tight sandstone using the digital core method. Their results revealed that cracks have a great influence on the microseepage law of tight reservoirs. Yang et al. [19] used the nuclear magnetic resonance (NMR) $\mathrm{T}_{2}$ spectrum to monitor the oil migration dynamics in tight oil reservoirs. Their results demonstrated that the small pores have a larger capillary pressure and stronger imbibition ability, and the small pores have a more effective oil recovery rate than the large pores. Compared with the matrix pores, the flow resistance in natural microcracks is smaller, which is more conducive to the flow of water and oil. Gu et al. [20] studied the microscopic influence mechanism of the permeability of tight reservoirs on the efficiency of imbibition oil recovery through spontaneous imbibition simulation, combined with nuclear magnetic resonance and computed tomography
(CT) analysis. Their research results revealed that spontaneous imbibition displacement of the matrix plays a vital role in the water injection development of tight sandstone reservoirs. The degree of spontaneous imbibition recovery from experimental core samples reached 5.24-18.23\%, and the greater the permeability of the matrix, the higher the spontaneous imbibition recovery degree.

At present, research on the seepage law of tight reservoirs has mainly focused on the influence of a certain type of pore, and no systematic combination of pores at all levels has been studied. The fluid flow in the actual reservoir is the result of the interactions between various pores. In this study, based on previous studies, two groups of online NMR experiments on water flooding and gas flooding were conducted using cores with different degrees of microcrack development, and the seepage law of a tight oil reservoir containing microcracks was studied. Based on this, the pore structures of tight oil reservoirs were graded according to their seepage characteristics, and a corresponding model was established. According to the characteristics of the model, a mathematical model was established to predict the energy parameters of the area where the cracks are not affected by cracking. In this paper, a multistage seepage model is established according to the seepage characteristics of tight reservoirs and the pore structure, which makes up for the deficiency of the previous classification of reservoirs only according to the pore structure, and provides a new research idea for the subsequent study of the seepage of tight reservoirs.

\section{Experiment}

To study the seepage law of tight oil reservoirs containing microcracks and to verify the multistage seepage model, two groups of online NMR experiments were conducted in this study. One group of experiments focused on the online NMR imbibition of water flooding, and the other group focused on the online NMR of gas flooding.

2.1. Experimental Materials. Eight outcrop cores $(25 \mathrm{~mm}$ in diameter and $50 \mathrm{~mm}$ in length) from the Chang 8 tight sandstone reservoir in the Huanxian area of the Ordos Basin were used. The basic core data are shown in Table 1 . The Ordos Basin is the most important oil-producing basin in China and is also the main distribution area of tight sandstone reservoirs. The Triassic Chang 8 reservoir is mainly composed of underwater distributary channel sedimentary sand, with a large thickness and stable distribution, and it is the main oil-bearing series in the study area.

The eight cores used in the experiments were matrix cores, of which cores 1-4 were similar samples and cores 58 were similar samples. The microcracks in cores $1-4$ and cores 5-8, which had different degrees of development, were produced using the triaxial stress shear fracture method for the two groups of online NMR experiments. The experimental flow chart of the core crack-making method is shown in Figure 1. During the crack-making process, firstly, a small axial pressure is loaded first to fix the core position, and then, load a fixed confining pressure, and it will always remain 
TABLE 1: Basic properties of cores.

\begin{tabular}{lccccc}
\hline Core number & Length/cm & Diameter/cm & Porosity/\% & Initial permeability/mD & Growth rate of crack permeability/\% \\
\hline 1 & 7.88 & 2.5 & 12.54 & 0.82 & 8.94 \\
2 & 7.91 & 2.5 & 13.02 & 0.91 & 27.18 \\
3 & 7.91 & 2.5 & 12.78 & 0.10 & 35.03 \\
4 & 7.94 & 2.5 & 13.12 & 1.24 & 62.87 \\
5 & 7.88 & 2.51 & 10.24 & 0.39 & 9.17 \\
6 & 7.88 & 2.53 & 10.68 & 0.42 & 14.17 \\
7 & 7.91 & 2.53 & 10.85 & 0.45 & 23.92 \\
8 & 7.84 & 2.52 & 1096 & 0.54 & 33.77 \\
\hline
\end{tabular}

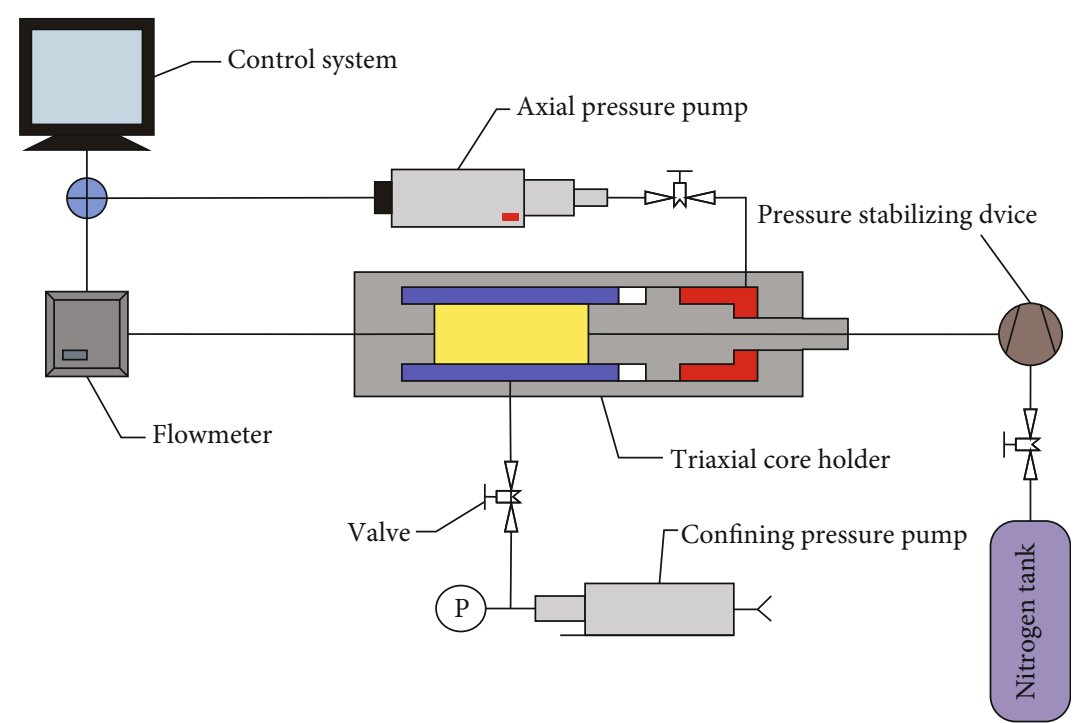

FIgURE 1: Flowchart of the experimental design of crack creation [21].

unchanged; secondly, set a suitable gas drive pressure to test the gas flow rate at the outlet end of the core holder to calculate the real-time permeability of the core; thirdly, set the axial pressure from 0 to $5 \mathrm{MPa}$, to $10 \mathrm{MPa}$, to $15 \mathrm{MPa}$, etc., until the gas permeability growth rate increases rapidly. The degree of microcracks was evaluated using the rate of change of the real-time permeability. A large number of microcracks were generated at the inflection point of the permeability, and cores with a certain degree of microcrack development were obtained by controlling the size of the axial pressure loading [21]. The core data after the crack-making process are presented in Table 1.

2.2. Experimental Process. The flow pattern in a tight oil reservoir containing microcracks was studied through two sets of online NMR experiments. The flow chart of the two experiments is shown in Figure 2. Experimental equipment consists of three parts: pressure system, online NMR testing system, and flow velocity testing system. The specific experimental steps are as follows.

The first set of water flooding experiments:

(1) Cores 1-4 were dried at $90^{\circ} \mathrm{C}$ for $24 \mathrm{~h}$, vacuumed for $24 \mathrm{~h}$, and saturated with kerosene
(2) The airtightness of the device shown in Figure 2(a) was checked, and the core was placed in the experimental equipment after the inspection was conducted

(3) The core holder was emptied, and the confining pressure was set to $10 \mathrm{MPa}$ to record the NMR signal. Manganese water with a manganese ion concentration of $8000 \mathrm{ppm}$ was used for the displacement. The displacement pressure was set to $8 \mathrm{MPa}$, and the backpressure was set to $3 \mathrm{MPa}$

(4) When the outlet began to produce water, the valves at the inlet and outlet were quickly closed, and the nuclear magnetic signal was recorded. After $12 \mathrm{~h}$, the nuclear magnetic signal was recorded, and the valves at the inlet and outlet were opened. The displacement in step (3) was restored until the oil production at the outlet was no longer stopped, and the nuclear magnetic signal was recorded

(5) At the end of the experiment, the data were processed

The second set of gas flooding experiments:

(1) Cores 5-8 were dried at $90^{\circ} \mathrm{C}$ for $24 \mathrm{~h}$, vacuumed for $24 \mathrm{~h}$, and saturated with kerosene 


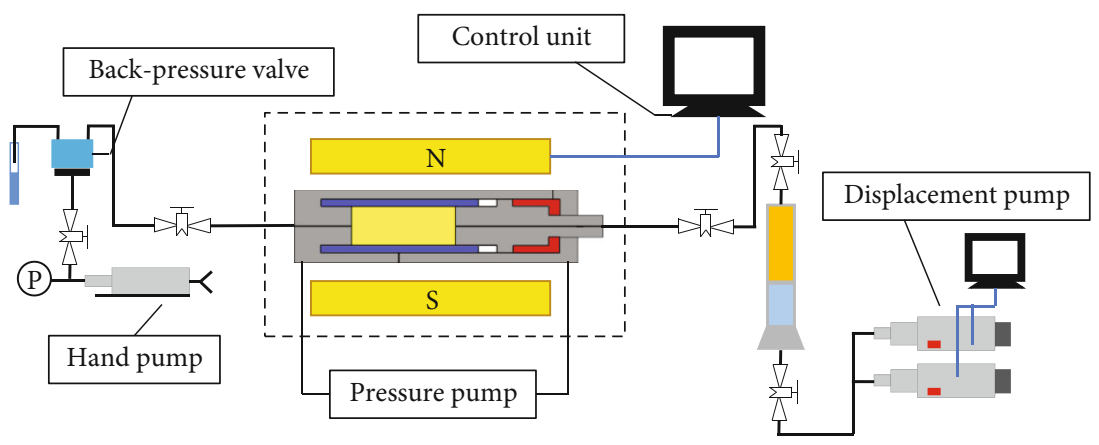

(a) Flow chart of water drive oil experiment

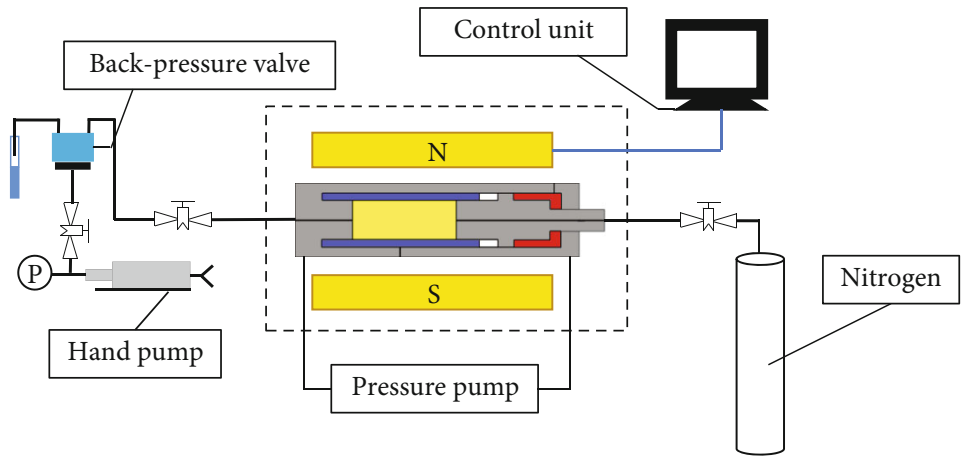

(b) Flow chart of gas drive oil experiment

FIgURE 2: Flow chart of online NMR experiment.

(2) The airtightness of the device shown in Figure 2(b) was checked, and the core was placed in the experimental equipment after the inspection

(3) The core holder was emptied, and the confining pressure was set to $10 \mathrm{MPa}$ to record the NMR signal. $\mathrm{N}_{2}$ was used for the displacement. The displacement pressure was set to $1 \mathrm{MPa}$, and the backpressure was set to $0.5 \mathrm{MPa}$

(4) The nuclear magnetic signal was recorded when bubbles began to appear at the outlet. After a period of gas flooding, the outlet no longer produced oil. At this time, the NMR signal was recorded, the inlet and outlet valves were closed, and the NMR signal was recorded after 12 hours. The inlet and outlet valves were opened, the displacement in step (3) was restored until the outlet no longer produced oil and the experiment ended, and the NMR signal was recorded

(5) At the end of the experiment, the data were processed

\section{Experimental Results and Discussion}

The theoretical basis of nuclear magnetic resonance (NMR) analysis is that the hydrogen nuclear ${ }^{1} \mathrm{H}$ contained in oil and water will excite different NMR signals in different relaxation times when encountering a specific frequency of the magnetic field. In the experiment, we often pay attention to the lateral relaxation time, which has a one-to-one correspondence with the pore radius [22]. According to the theo- retical analysis of $\mathrm{NMR}$, the $\mathrm{NMR} \mathrm{T}_{2}$ spectrum of rock saturated single-phase fluid can reflect its internal pore structure. The atomic transverse relaxation time of a single channel of saturated water in a uniform magnetic field can be approximately expressed as [23]:

$$
\frac{1}{T_{2}}=\rho_{2} \frac{S}{V},
$$

where $T_{2}$ is transverse relaxation time (ms). $\rho_{2}$ is transverse surface relaxation strength, depending on pore surface properties and mineral composition and saturated fluid properties $(\mu \mathrm{m} / \mathrm{ms}) . S / V$ is the specific surface of a single pore $\left(\mu \mathrm{m}^{2} / \mu \mathrm{m}^{3}\right)$.

By analyzing the amplitude and transverse relaxation time of the NMR signal, we can obtain the information of rock pore structure and fluid content in pore space.

3.1. Online NMR Water Flooding Oil Experiments. Figure 3 shows the $T_{2}$ curves of cores 1-4 during four different displacement stages of the water flooding process. The four stages are the completion of oil saturation, water-oil displacement, imbibition, and water-oil displacement after imbibition. As can be seen from the saturated oil curve and water flooding curve, after the first water flooding stage, the space for pore reduction was mainly the larger pores on the right side, and the smaller pores on the left side were not used, indicating that during the water flooding process, the effective seepage channels are the large pores and microcracks. As can be seen from the curve after water flooding and the curve after soaking, the left NMR $T_{2}$ signal 

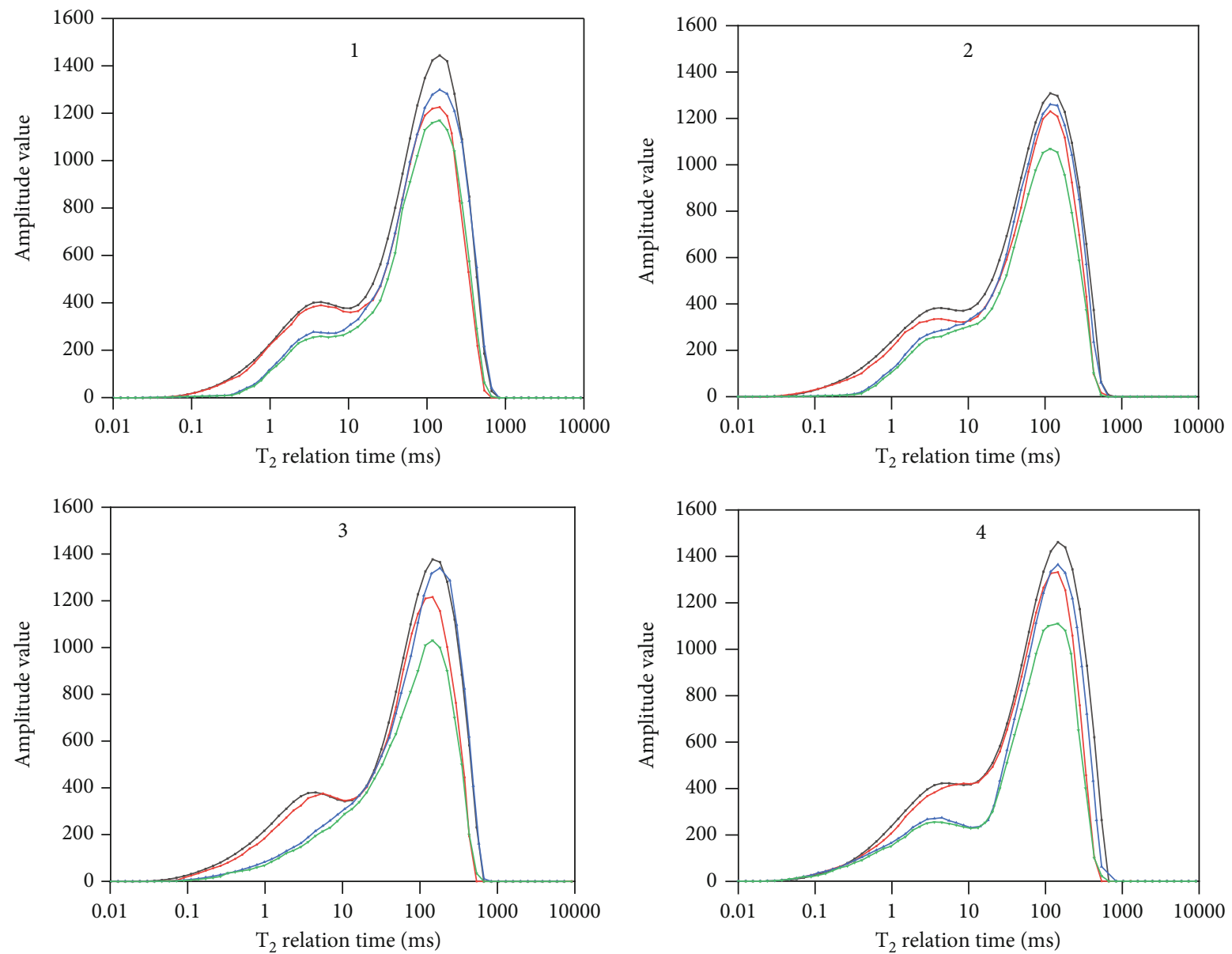

$\begin{array}{ll}\text { - Saturated oil } & \text { Imbibition } \\ \text { - Water-oil displacement } & - \text { Water-oil displacement after imbibition }\end{array}$

Figure 3: Comparison of the $T_{2}$ curves of the water flooding oil in different displacement stages.

decreased, and the right NMR $T_{2}$ signal increased after soaking, indicating that the imbibition effect was significant. The oil in the small holes was replaced by that in the large holes, making it difficult to displace the oil in the small holes. By observing the two displacement processes before and after the occurrence of imbibition, it was found that the change in the oil in the small holes was small, indicating that during the displacement process, the main channel of oil-water twophase flow was the large holes, and the change in the oil in the small holes during the two processes was mainly the amount of imbibition during the displacement process.

Figure 4 shows the variation in the oil content in the pores during the different displacement stages. In the pore size classification, NMR relaxation times of $5 \mathrm{~ms}, 10 \mathrm{~ms}$, and $100 \mathrm{~ms}$ were used to divide the nanopores, micro-nanopores, submicron pores, and micron pores [16, 24]. It can be seen from the diagram that the quantity of the nanopores and micro-nanopores indicated by the signal decreased from the water flooding to the imbibition stages. The number of nanopores in cores 1-4 indicated by the signal decreased by $40 \%, 36 \%, 45 \%$, and $19 \%$, respectively, and the number of micro-nanopores indicated by the signal decreased by $25 \%, 5 \%, 25 \%$, and $39 \%$, respectively. In cores $1-4$, the num- ber of micron pores indicated by the signal increased by $17 \%, 11 \%, 27 \%$, and $28 \%$, respectively, demonstrating that the imbibition mainly involved transferring the oil in the nanopores and micro-nanopores into the micron pores, and imbibition production accounted for $6.8 \%, 5.0 \%$, $11.3 \%$, and $11.0 \%$ of the initial oil content, respectively. In cores 1 and 2, the imbibition mainly transferred the oil in the $<100 \mathrm{~nm}$ pores into the macropores. The oil content of the submicron pores increased by less than $1 \%$ and $1.3 \%$, respectively. In cores 3 and 4 , the oil in the $<1000 \mathrm{~nm}$ pores was transferred to the large pores. At this time, the oil content of the submicron pores decreased by $1.4 \%$ and $5.3 \%$, respectively. Because the imbibition occurred under the action of a capillary force, the degree of microcrack development in cores 3 and 4 was high, and there were many submicron pores connected by microcracks, resulting in the oil in the submicron pores being transferred to the microcracks. If only two displacement processes, i.e., before and after imbibition, are considered, the change in the oil content mainly occurred in the micron pores, indicating that the twophase flow of the water flooding oil mainly occurred in the larger pores such as the micron pores, and there was no two-phase flow in the nanopores and micro-nanopores. 

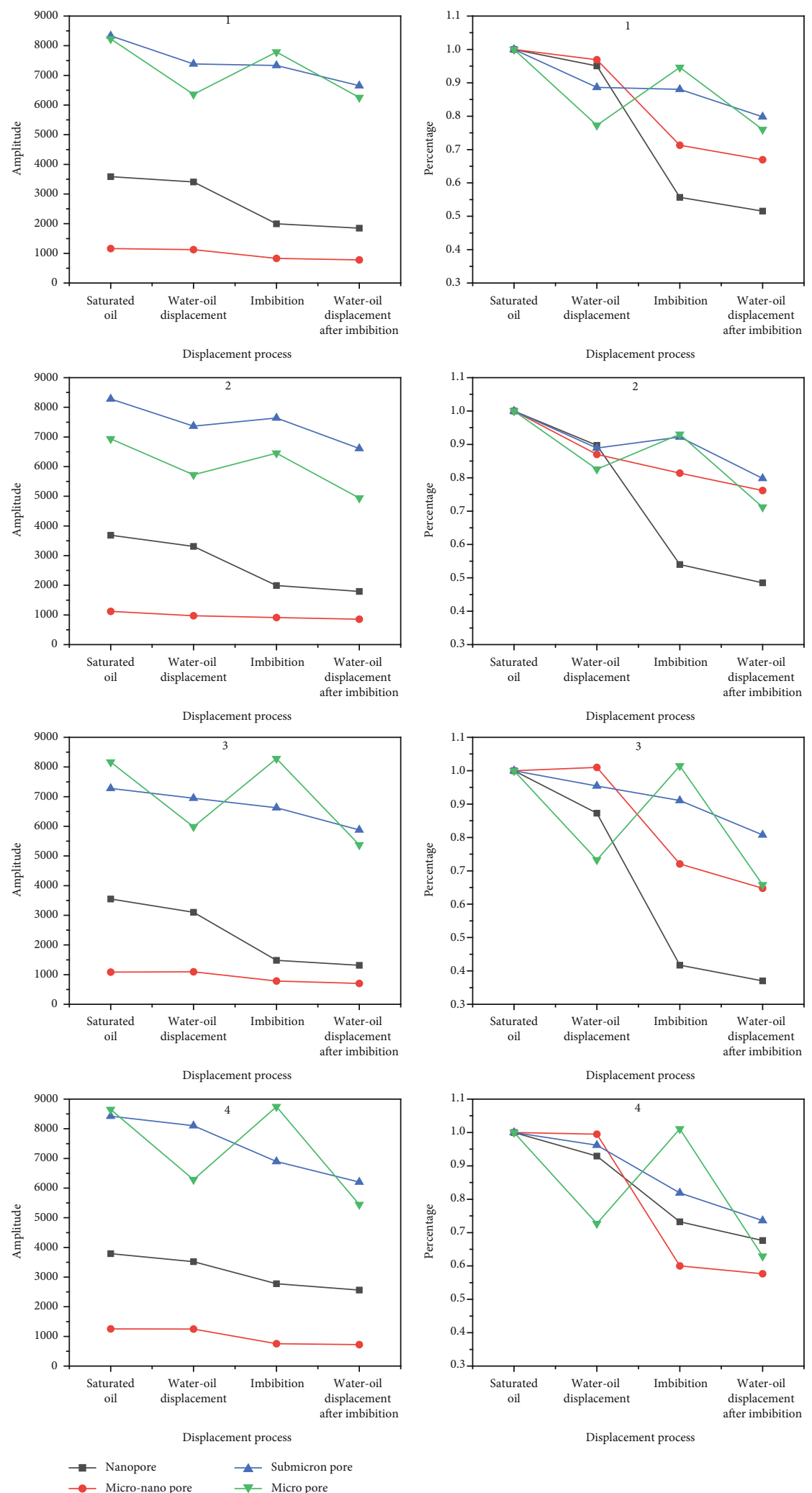

Displacement process

FIGURE 4: Comparison of the changes in the oil contents of the various types of pores under different displacement conditions.

3.2. Online $N M R$ Gas Driven Oil Experiments. Figure 5 shows the $T_{2}$ curves of the five different displacement stages during gas flooding for cores $5-8$. The five stages are oil sat- uration, the appearance of bubbles in the gas flooding oil, no oil production of gas flooding oil, well soaking, and no oil production after well soaking. It can be seen from the 

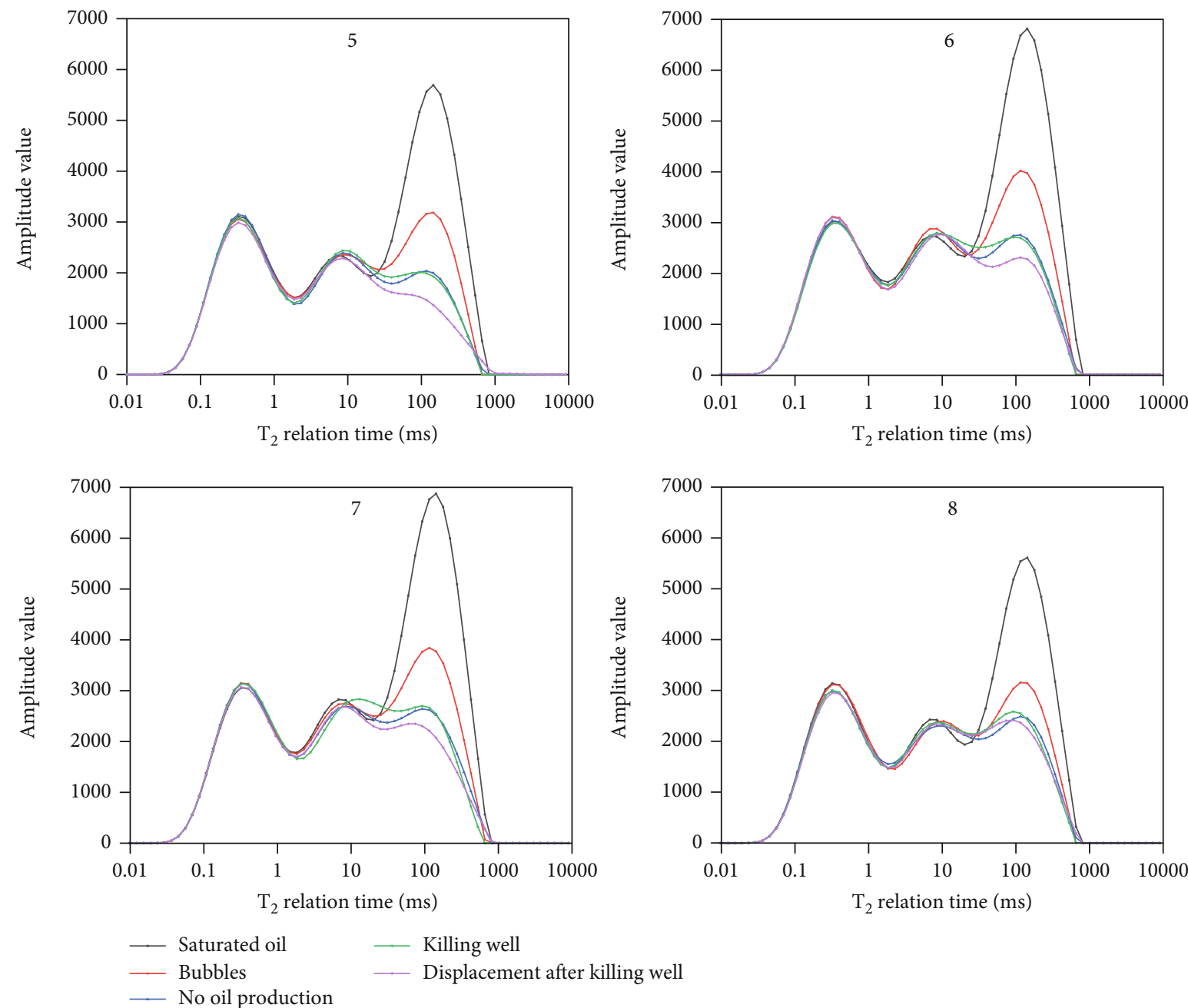

— Killing well

—_ Displacement after killing well

Figure 5: Comparison of the $T_{2}$ curves from the gas-driven oil experiments during the different displacement stages.

diagram that during the two gas flooding processes, the left NMR $T_{2}$ signal remained unchanged, while the right NMR $T_{2}$ signal decreased more in the first gas flooding and less in the second gas flooding, indicating that during the two gas flooding processes, the oil in the small pores was not used, and there was no imbibition during the well soaking stage. The main seepage channels of the fluid during the displacement process were the large pores and microcracks. The slight change in the NMR $T_{2}$ signal in the middle and right side of the well before and after the soaking was caused by the gas is in the middle position of the pores during the gas displacement process, which resulted in the instability of the oil film thickness carried by the nitrogen flow and the redistribution during the soaking process. This resulted in a change in the signal of the crude oil in the larger and middle pores. As the microcrack development increased, the change in the signal before and after soaking gradually decreased. This indicates that the more microcracks, the shorter the time to reach equilibrium and stability during the gas flooding process and the smaller the change in the signal after soaking.

Figure 6 shows the variation in the oil content of the pores during the different gas driven stages. It can be seen from the diagram that the degree of the utilization of the nanopores and micro-nanopores in the four cores was very low throughout the entire experiment. In cores $5-8$, it was $<4 \%,<2 \%, 2-6 \%$, and $<5 \%$, respectively. The degree of utilization of the micron pores in cores $5-8$ was $76 \%, 68 \%, 70 \%$, and $60 \%$, respectively. The degree of utilization of the submicron pores in cores $5-8$ was $39 \%, 33 \%, 35 \%$, and $23 \%$, respectively. This shows that the main seepage channels of the fluid during the gas flooding were the large pores and microcracks. There was almost no change in the residual oil signal in the various pores before and after soaking, indicating that no imbibition occurred.

3.3. Comparison of the Two Sets of Displacement Experiments. Figure 7 shows the variation in the residual oil saturation during the different stages of water flooding and gas flooding under different flooding conditions. It can be seen from the water flooding process that the residual oil saturation after the first water flooding was $85 \%$, and after the second water flooding and after soaking, the residual oil saturation decreased to $70 \%$, indicating that the permeability had a large impact on the oil recovery during water flooding. As the microcrack development increased, 

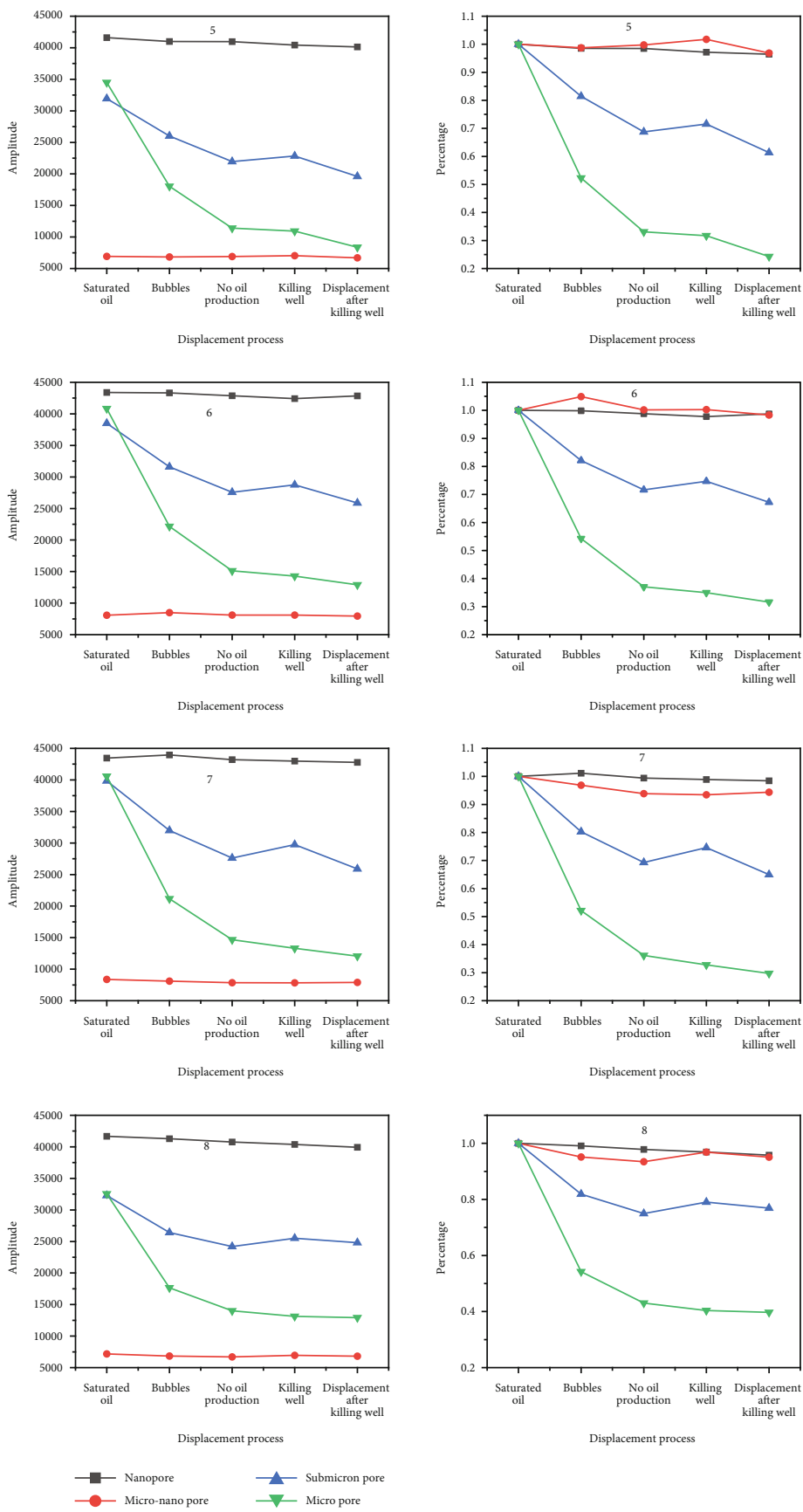

FIGURE 6: Comparison of the changes in the oil contents of the various types of pores during gas flooding.

the final recovery rate initially increased and then decreased. This is because with the increase of the degree of microcrack development, the fluid flowability increases, and the recovery rate increases. When the microcrack is too developed, the fluid will flow in tandem, resulting in reduced recovery. From the gas flooding process, it was found that after the first gas flooding stage, the remaining oil saturation of core 8 was $75 \%$, and the remaining oil saturation of cores $5-7$ was $70 \%$. After the second displacement during the well soaking, the remaining oil saturation of core 8 decreased slightly, and the remaining oil saturation of cores 6-8 decreased by $2-5 \%$. This shows that the effect of well soaking on recovery is low, and the higher the degree of microcrack development, the lower the ultimate recovery. This is because gas channeling occurs in the process of gas flooding. The higher the development degree of microcracks is, the more serious the gas channeling is, resulting in lower oil production.

\section{Establishing the Model}

In a tight reservoir without artificial modification, the microcracks mainly connect the intergranular pores and intragranular pores to form seepage channels. Figure 8 shows second 

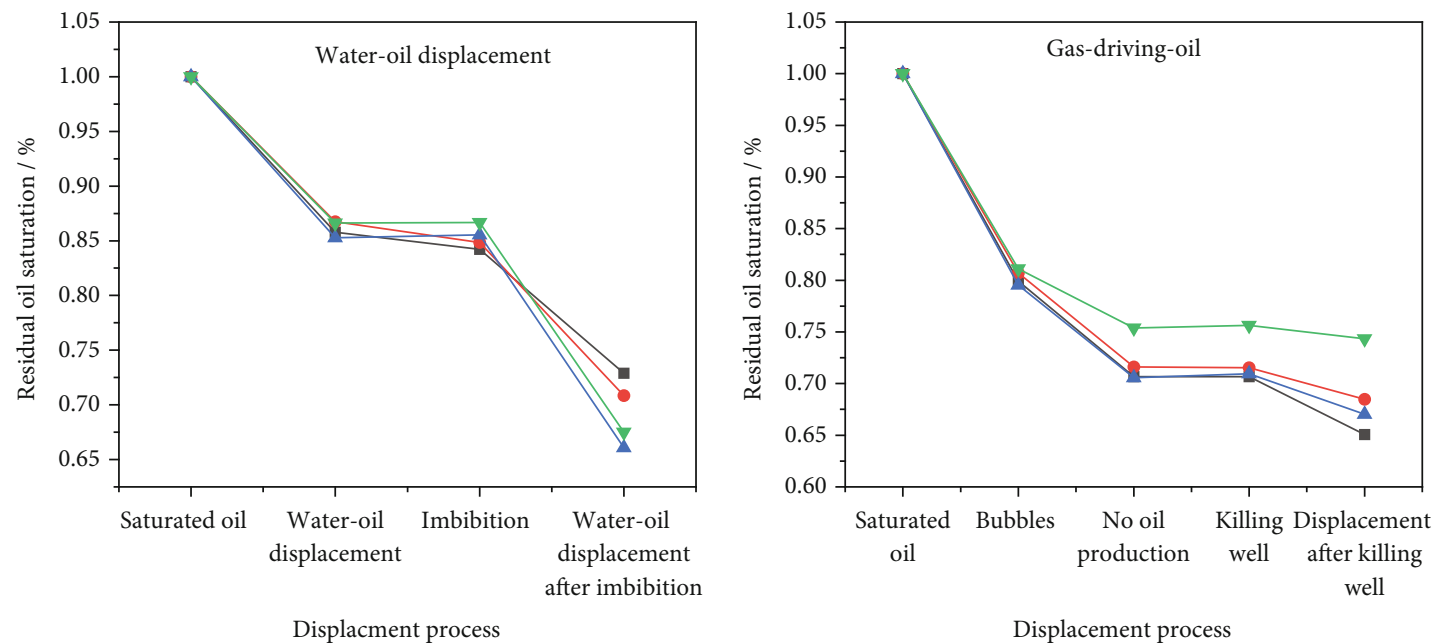

$$
\begin{aligned}
& -1 \\
& -2 \\
& -3 \\
& -4
\end{aligned}
$$

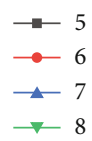

Figure 7: Diagrams showing the residual oil saturation in different states under two displacement modes.

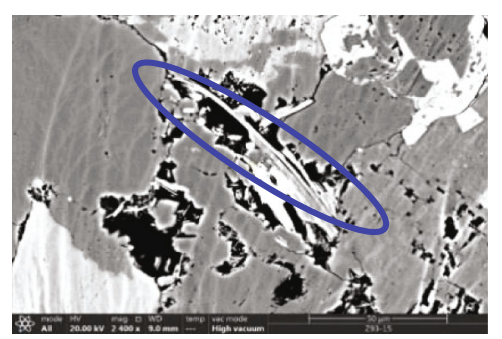

(a)

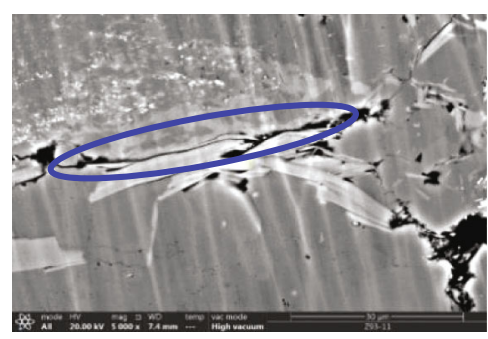

(c)

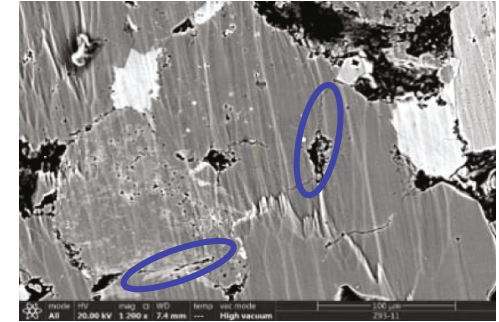

(b)

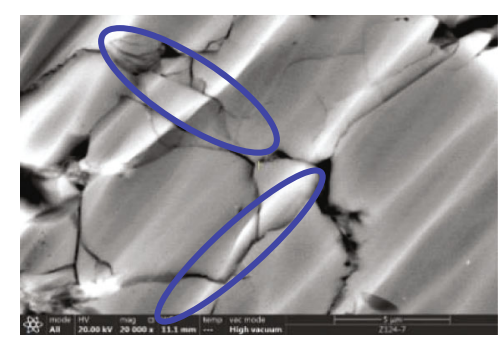

(d)

FIGURE 8: Three-beam argon ion etching polished FIB-SEM images.

and third beam argon ion etching polished focused ion beam-scanning electron microscope (FIB-SEM) images of the tight sandstone of the Chang 7 reservoir. As can be seen from the images, the microcracks are continuous, the intergranular pores are isolated, and the microcracks connect the intergranular pores and other pores.

Figure 9 shows the rock sample nano-CT profile. It can be seen in the diagram that owing to the dense nature of the rock, the connecting channels between the original intergranular pores are also filled. In some of the pores, the original intergranular pores cannot be connected and must be connected through microcracks. Therefore, the microcracks and the large pores connected by them are the main effective channels for seepage in tight reservoirs.

4.1. Conceptual Model. It can be seen from Figures 8 and 9 that microcracks and large pores are the bridges connecting various parts of the tight reservoir and are the main seepage channels. This is also the basis of understanding the concept of multistage seepage in the tight reservoir. According to the above experimental results, the main seepage channels in tight reservoirs are the microcracks and the large pores they connect, whose size is mainly $>100 \mathrm{~nm}$, which is the main location of oil-water two-phase flow. There is no two- 

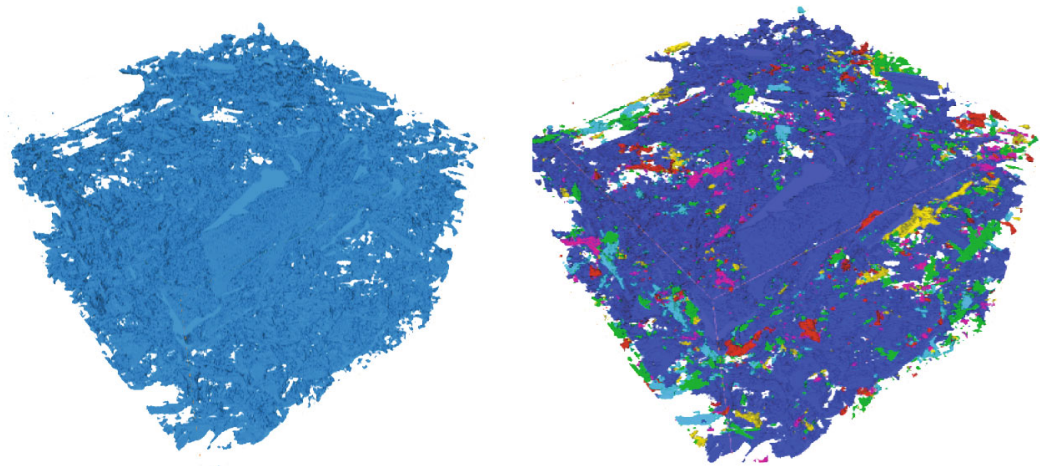

FIgURE 9: Nano CT profile of the Chang 7 reservoir rock samples.

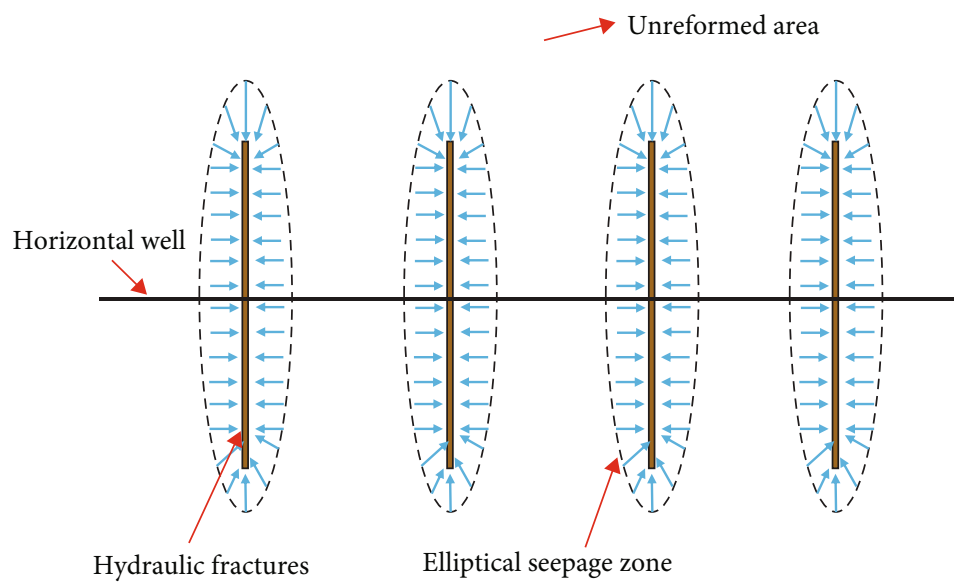

Figure 10: Schematic diagram of the seepage zoning of tight reservoirs.

phase flow in the small pores $(<100 \mathrm{~nm})$. The main reason for this is that oil is replaced by imbibition [25]. Owing to the pore-scale effect, the production of tight reservoirs is a complex crossscale process: from the unreformed area to the area affected by the hydraulic fractures to the hydraulic cracks and finally to the wellbore [26-29]. The main research object of this study was an unreformed tight oil reservoir (Figure 10). According to the seepage characteristics of tight reservoirs, the influences of the different size pores on seepage were classified into grades. In this study, a conceptual model of multistage seepage in tight reservoirs is proposed. This model mainly applies to the matrix seepage area that is not affected by fracturing cracks. This area is generally far away from the artificial cracks, and it differs from the seepage law of large cracks. The specific surface areas in this region are large, and the viscosity is high. The model is shown in Figure 11. The following assumptions are made in this model.

(1) The model divides the pores in the reservoir into three grades according to their flow size: primary pores, secondary pores, and tertiary pores. Among them, the primary pores mainly refer to the microcracks in the reservoir and the large pores connected by them, and their main size is $>100 \mathrm{~nm}$. The sec- ondary pores are $50-100 \mathrm{~nm}$. The tertiary pores are $<50 \mathrm{~nm}$ nanopores

(2) During water injection development, owing to the small pore space represented by the secondary pores and tertiary pores, these two types of pores are only involved in the oil-water absorption process, that is, the water driven oil flow only occurs in the primary pores. The primary pores include the macropores, throats, and microcracks

(3) In the water injection development of tight reservoirs, the oil is displaced from the small pores and transferred to the large pores through imbibition, and thus, it can participate in the oil-water flow. The displaced oil exists in the water in the form of a dispersed phase, resulting in two-phase interfacial resistance. The Jamin effect caused by the multiinterface phenomenon is the main resistance in the water injection development process, and the resistance gradient is also far greater than the threshold pressure gradient

In this model, the flow of oil and water is divided into two parts: the imbibition displacement process and the oil and water two-phase flow process in the primary pores. 


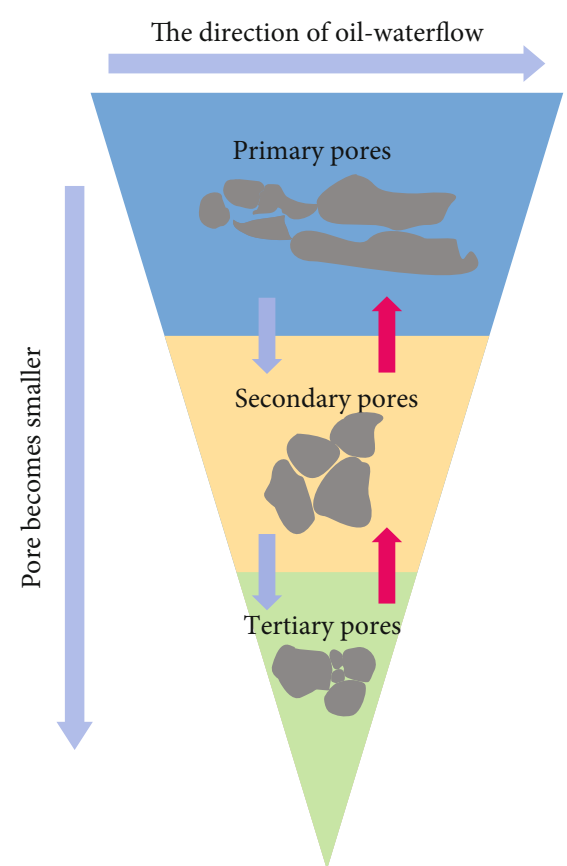

Figure 11: Conceptual model of multistage seepage in tight reservoir.

During the imbibition process, the capillary force acts as a local force to transfer the oil from the secondary and tertiary pores to the primary pores and provides the power needed for it to participate in the oil-water two-phase flow [30].

In the primary pores, the Jamin effect caused by the multi-interface flow greatly increases the difficulty of water injection development. Based on this model, the water flooding process can be subdivided into the following processes: (1) the displacement process occurs in the first stage pores. The oil saturation in the first stage pores decreases, and the water saturation increases. (2) The oil-water displacement process occurs between the primary pores and the secondary pores. The oil saturation in the first-stage pores increases, and the oil saturation in the second-stage pores decreases. (3) The oil-water displacement occurs between the secondstage pores and the tertiary pores. The oil saturation in the second-stage pores increases, and the oil saturation in the third-stage pores decreases. (4) The displacement in the first stage pores removes the increased crude oil. Through the above cycle, the displacement of the low permeability tight crude oil is realized.

4.2. Mathematical Model. In this section, based on the above conceptual multistage seepage model from tight reservoirs, a mathematical total productivity prediction model considering imbibition is established. The mathematical model derived in this paper is based on the conceptual model of multistage seepage law in tight reservoirs. Considering the influence of seepage classification, it is considered that oilwater two-phase flow occurs only in primary pores, and other pores participate in fluid flow through imbibition. In this

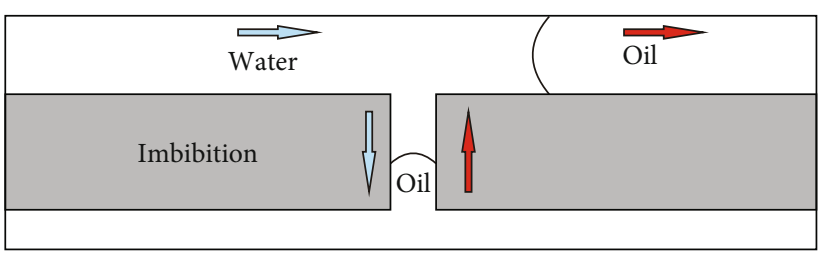

FIgURE 12: Schematic diagram of imbibition in the multistage seepage process.

paper, the calculation is carried out by considering the characteristics of microcracks in the flow.

4.2.1. Imbibition Model. Imbibition occurs under the action of the capillary force, which cannot be ignored in tight reservoirs [31]. In the imbibition process, the capillary force supplies the power to replace the oil in the secondary and tertiary pores with the water in the primary pores [32]. This process is shown in Figure 12. The capillary force can be expressed as

$$
F_{c}=\frac{2 \sigma \cos \theta}{r} \pi r^{2}=2 \pi \sigma r \cos \theta
$$

where $F_{c}$ is the capillary force $(\mathrm{N}) . \sigma$ is the interfacial tension between the oil and water $(\mathrm{N} / \mathrm{m}), r$ is the capillary radius (m). $\theta$ is the contact angle. The viscous resistance of the oil and water in the capillary is expressed as follows:

$$
\begin{aligned}
f & =2 \pi r x \tau_{w}+2 \pi r(L-x) \tau_{o}, \\
\tau_{w} & =-\frac{4 \mu_{w}}{r} v_{w} \\
\tau_{o} & =-\frac{4 \mu_{o}}{r} v_{o}
\end{aligned}
$$

where $f$ is the viscous resistance $(\mathrm{N}) . x$ is the distance between the two-phase contact surface and the beginning of the capillary (m). $\tau_{w}$ and $\tau_{o}$ are the shear stress of water and oil $\left(\mathrm{N} / \mathrm{m}^{2}\right) . L$ is the total distance of infiltration $(\mathrm{m})$. According to Newton's second law, the force analysis of fluid in the capillary tube can be obtained:

$$
F_{c}+f=m a \Leftrightarrow 2 \pi \sigma r \cos \theta-8 \pi\left(x \mu_{w}+(L-x) \mu_{o}\right) \frac{d x}{d t}=m \frac{d^{2} x}{d t^{2}} .
$$

Since the inertial force term in Equation (6) is relatively small, by ignoring the second-order derivative term in Equation (6), we can obtain

$$
\sigma r \cos \theta-4\left(x \mu_{w}+(L-x) \mu_{o}\right) \frac{d x}{d t}=0
$$


By solving Equation (7), $x$ can be expressed as

$$
x=\frac{2 \mu_{o} L-\sqrt{4\left(\mu_{o} L\right)^{2}-2\left(\mu_{o}-\mu_{w}\right) \sigma r \cos \theta t}}{2\left(\mu_{o}-\mu_{w}\right)} .
$$

Therefore, the oil yield of a single capillary can be expressed as

$$
q=\pi r^{2} x=\pi r^{2} \frac{2 \mu_{o} L-\sqrt{4\left(\mu_{o} L\right)^{2}-2\left(\mu_{o}-\mu_{w}\right) r \cos \theta t}}{2\left(\mu_{o}-\mu_{w}\right)} .
$$

To obtain the oil production of all of the capillary tubes during imbibition, we assume that the pore size of the capillary tubes obeys a Gaussian distribution:

$$
\begin{aligned}
f(r) & =\frac{1}{\sqrt{2 \pi} f_{1}} \exp \left(-\frac{\left(r-f_{2}\right)^{2}}{2 f_{1}^{2}}\right), \\
\int_{r_{\min }}^{r_{\max }} f(r) & =1,
\end{aligned}
$$

where $f(r)$ is the distribution function of the capillary aperture, $f_{1}$ is the standard deviation, and $f_{2}$ is the average distribution.
The relationship between the total capillary number and the pore size distribution function can be expressed as

$$
d N=f(r) N d r
$$

where $N$ is the total number of capillaries.

The total pore volume can be expressed as

$$
\begin{aligned}
V_{p} & =\int_{r_{\min }}^{r_{\max }} \pi r^{2} L d N=\pi L N \int_{r_{\text {min }}}^{r_{\text {max }}} f(r) r^{2} d r, \\
V_{p} & =\pi\left(R^{2}-x_{f}^{2}\right) h \phi,
\end{aligned}
$$

where $R$ is the outer boundary radius of the infiltration region $(\mathrm{m}) \cdot x_{f}$ is the inner boundary radius (half-length of the crack) of the imbibition region $(m) . h$ is the thickness of the infiltration area $(\mathrm{m}) . \oint$ is the porosity of the infiltration area (\%).

By solving Equation (13) and Equation (14), we can obtain

$$
N=\frac{\left(R^{2}-x_{f}^{2}\right) h \phi}{\left(L / \sqrt{2 \pi} f_{1}\right) \int_{r_{\text {min }}}^{r_{\max }} r^{2} \exp \left(-\left(\left(r-f_{2}\right)^{2} / 2 f_{1}^{2}\right)\right) d r} .
$$

Therefore, the oil production absorbed into the fluid flow channel under the influence of the capillary force is

$$
Q=\int_{r_{\min }}^{r_{\max }} q d N=\frac{\left(R^{2}-x_{f}^{2}\right) h \phi \pi \int_{r_{\min }}^{r_{\max }} r^{2}\left(\left(2 \mu_{o} L-\sqrt{4\left(\mu_{o} L\right)^{2}-2\left(\mu_{o}-\mu_{w}\right) r \cos \theta t}\right) /\left(2\left(\mu_{o}-\mu_{w}\right)\right)\right) \exp \left(-\left(\left(r-f_{2}\right)^{2} / 2 f_{1}^{2}\right)\right) d r}{L \int_{r_{\min }}^{r_{\max }} r^{2} \exp \left(-\left(\left(r-f_{2}\right)^{2} / 2 f_{1}^{2}\right)\right) d r} .
$$

4.2.2. Productivity Prediction Model for Primary Pores. In the primary pores of tight reservoirs, owing to the existence of microcracks and throats, factors such as the stress sensitivity, threshold pressure gradient, and the Jamin effect need to be considered in the model [18]. The stress sensitivity can be expressed as [33]

$$
K=K_{i} e^{-\alpha_{k}\left(P_{i}-P\right)},
$$

where $\alpha_{k}$ is the stress sensitivity coefficient $\left(\mathrm{MPa}^{-1}\right) . P_{i}$ is the initial reservoir pressure $(\mathrm{MPa}) . P$ is the reservoir pressure $(\mathrm{MPa}) . K_{i}$ is the initial permeability of the reservoir.

The two-phase flow motion equation considering the stress sensitivity, threshold pressure gradient, and Jamin effect is as follows:

$$
\frac{d P}{d r}-\lambda_{o}-P_{c j}=\frac{\mu_{o}}{K_{r o}} \cdot \frac{v_{o}}{K_{i} e^{-\alpha_{k}\left(P_{i}-P\right)}},
$$

$$
\frac{d P}{d r}-\lambda_{w}-P_{c j}=\frac{\mu_{w}}{K_{r w}} \cdot \frac{v_{w}}{K_{i} e^{-\alpha_{k}\left(P_{i}-P\right)}},
$$

where $r$ is the distance between the formation and the bottom hole $(\mathrm{m}) . \lambda_{o}$ is the oil phase threshold pressure gradient $(\mathrm{MPa} / \mathrm{m}) . P_{c j}$ is Jamin resistance $(\mathrm{MPa} / \mathrm{m}), \mu_{o}$ is the oil viscosity $(\mathrm{mPa} \cdot \mathrm{s}) . K_{r o}$ is oil relative permeability. $\nu_{o}$ is the seepage velocity of the oil phase $(\mathrm{m} / \mathrm{s}) . \lambda_{w}$ is the threshold pressure gradient of the water phase $(\mathrm{MPa} / \mathrm{m}) . \mu_{w}$ is water viscosity (mPa.s). $K_{r w}$ is water relative permeability. $v_{w}$ is the seepage velocity of the water phase $(\mathrm{m} / \mathrm{s})$.

We can expand $e^{-\alpha_{k}\left(P_{i}-P\right)}$ to obtain Equation (20) using the Taylor formula:

$$
\begin{aligned}
e^{-\alpha_{k}\left(P_{i}-P\right)}=1 & -\alpha_{k} e^{-\alpha_{k}\left(P_{i}-P\right)}\left(P_{i}-P\right)-\cdots \\
& -\frac{\alpha_{k}^{j} e^{-\alpha_{k}\left(P_{i}-P\right)}\left(P_{i}-P\right)^{j}}{j !}-\cdots-\frac{\alpha_{k}^{n} e^{-\alpha_{k}\left(P_{i}-P\right)}\left(P_{i}-P\right)^{n}}{n !},
\end{aligned}
$$

$$
j=1,2 \cdots \cdots n, n=1,2,3 \cdots \cdots
$$


TABLE 2: Basic model calculation parameters.

\begin{tabular}{lccc}
\hline Basic parameters & Value & Basic parameters & Value \\
\hline Porosity $(\%)$ & 12 & Minimum porous aperture $(\mu \mathrm{m})$ & 0.01 \\
Permeability $(\mathrm{mD})$ & 0.7 & Maximum porous aperture $(\mu \mathrm{m})$ & 5 \\
Oil viscosity $(\mathrm{mPa} \cdot \mathrm{s})$ & 2.21 & Residual oil saturation $(\%)$ & 20 \\
Water viscosity $(\mathrm{mPa} \cdot \mathrm{s})$ & 1 & Bound water saturation $(\%)$ & 20 \\
Contact angle & $30^{\circ}$ & Relative permeability of oil phase under bound water saturation $(\%)$ & 83 \\
Oil-water interfacial tension $(\mathrm{mN} / \mathrm{m})$ & 35.5 & External boundary radius $(\mathrm{m})$ & 1000 \\
Internal boundary radius $(\mathrm{m})$ & 10 & Effective reservoir thickness $(\mathrm{m})$ & 10 \\
\hline
\end{tabular}

Since the stress sensitivity coefficient $\alpha_{k}$ is $<<1$, the threshold pressure gradient $\lambda_{o}$ is $<<1, \lambda_{w}<<1$, and the Jamin resistance $P_{c j}$ is $<<1$, Equation (20) can be replaced by Equation (18) and Equation (19) and simplified as follows:

$$
\begin{aligned}
& e^{-\alpha_{k}\left(P_{i}-P\right)} \frac{K_{r o}}{\mu_{o}} \cdot \frac{d P}{d r}=\frac{v_{o}}{K_{i}}+\frac{K_{r o}}{\mu_{o}} \lambda_{o}+\frac{K_{r o}}{\mu_{o}} P_{c j}, \\
& e^{-\alpha_{k}\left(P_{i}-P\right)} \frac{K_{r w}}{\mu_{w}} \cdot \frac{d P}{d r}=\frac{v_{w}}{K_{i}}+\frac{K_{r w}}{\mu_{w}} \lambda_{w}+\frac{K_{r w}}{\mu_{w}} P_{c j} .
\end{aligned}
$$

According to the oil-water two-phase flow differential equation (Equations (21) and (22)), the oil-water twophase productivity equation can be obtained as follows:

$$
\int_{P_{2}}^{P_{1}} \frac{e^{-\alpha_{k}\left(P_{i}-P\right)} K_{r o}}{B_{o} \mu_{o}} d P=\frac{q_{o}}{2 \pi h K_{i}} \int_{r_{2}}^{r_{1}} \frac{1}{r} d r+\left(\lambda_{o}+P_{c j}\right) \int_{r_{2}}^{r_{1}} \frac{K_{r o}}{B_{o} \mu_{o}} d r,
$$

$$
\int_{P_{2}}^{P_{1}} \frac{e^{-\alpha_{k}\left(P_{i}-P\right)} K_{r w}}{B_{w} \mu_{w}} d P=\frac{q_{w}}{2 \pi h K_{i}} \int_{r_{2}}^{r_{1}} \frac{1}{r} d r+\left(\lambda_{w}+P_{c j}\right) \int_{r_{2}}^{r_{1}} \frac{K_{r w}}{B_{w} \mu_{w}} d r
$$

where $P_{1}$ is the external boundary pressure $(\mathrm{MPa}) . P_{2}$ is internal boundary pressure (MPa). $r_{1}$ is the outer boundary radius $(\mathrm{m}), r_{2}$ is the inner boundary radius $(\mathrm{m}) . B_{o}$ is the volume coefficient of the oil phase $\left(\mathrm{m}^{3} / \mathrm{m}^{3}\right) . B_{w}$ is the water volume coefficient $\left(\mathrm{m}^{3} / \mathrm{m}^{3}\right)$.

From Equation (23), we can obtain

$$
Q_{o}=2 \pi h K_{i} \frac{K_{r o} e^{-\alpha_{k} P_{i}}\left(e^{\alpha_{k} P_{1}}-e^{\alpha_{k} P_{2}}\right)-K_{r o} \alpha_{k}\left(\lambda_{o}+P_{c j}\right)\left(r_{1}-r_{2}\right)}{B_{o} \mu_{o} \alpha_{k} \ln r_{1} / r_{2}},
$$

$$
m=2 \pi h K_{i} \frac{e^{-\alpha_{k} P_{i}}\left(e^{\alpha_{k} P_{1}}-e^{\alpha_{k} P_{2}}\right)-\alpha_{k}\left(\lambda_{o}+P_{c j}\right)\left(r_{1}-r_{2}\right)}{B_{o} \mu_{o} \alpha_{k} \ln r_{1} / r_{2}} .
$$

Then, the yield equation can be expressed as

$$
Q_{o}=m K_{r o} .
$$

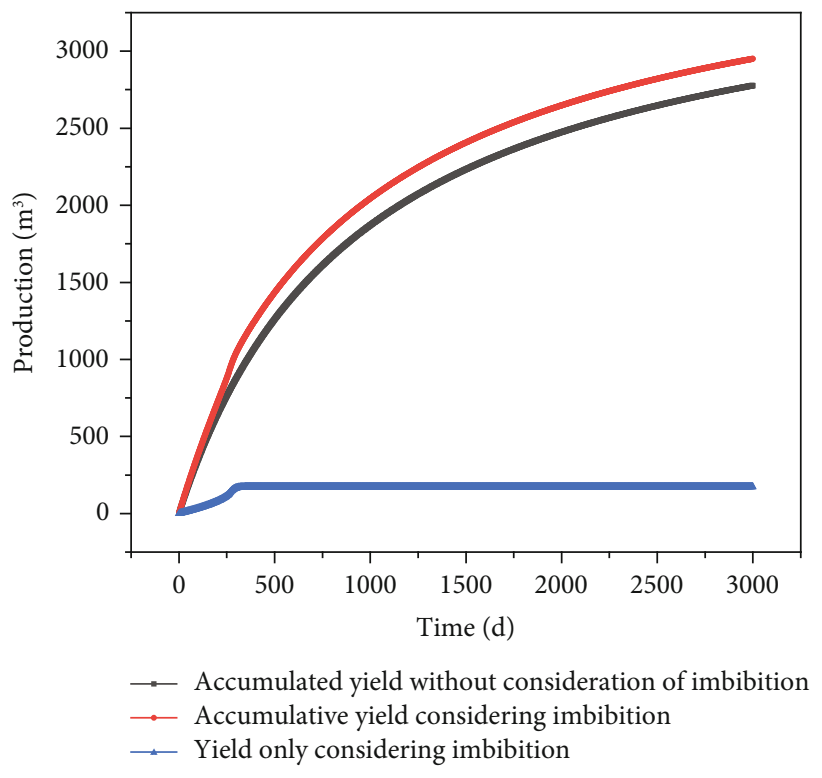

Figure 13: Diagram of cumulative yield.

From the material balance equation, we can obtain

$$
Q_{o}=\frac{V_{p}}{B_{o}} \frac{d \overline{S_{w}}}{d t},
$$

where $V_{p}$ is the pore volume $\left(\mathrm{m}^{3}\right) \cdot \overline{S_{w}}$ is the average water saturation (decimal). $t$ is production time (d).

From Equations (25) and (28), we can obtain

$$
\frac{1}{K_{r o}} d \overline{S_{w}}=\frac{m B_{o}}{V_{p}} d t
$$

The relative permeability curve of oil and water can be expressed as follows:

$$
\begin{aligned}
& K_{r o}=K_{r o}\left(S_{w c}\right)\left(\frac{1-S_{w}-S_{\mathrm{or}}}{1-S_{w c}-S_{\mathrm{or}}}\right)^{n_{o}}, \\
& K_{r w}=K_{r w}\left(S_{\mathrm{or}}\right)\left(\frac{S_{w}-S_{w c}}{1-S_{w c}-S_{\mathrm{or}}}\right)^{n_{w}},
\end{aligned}
$$

where $n_{o}$ is oil phase index and $n_{w}$ is water phase index. 

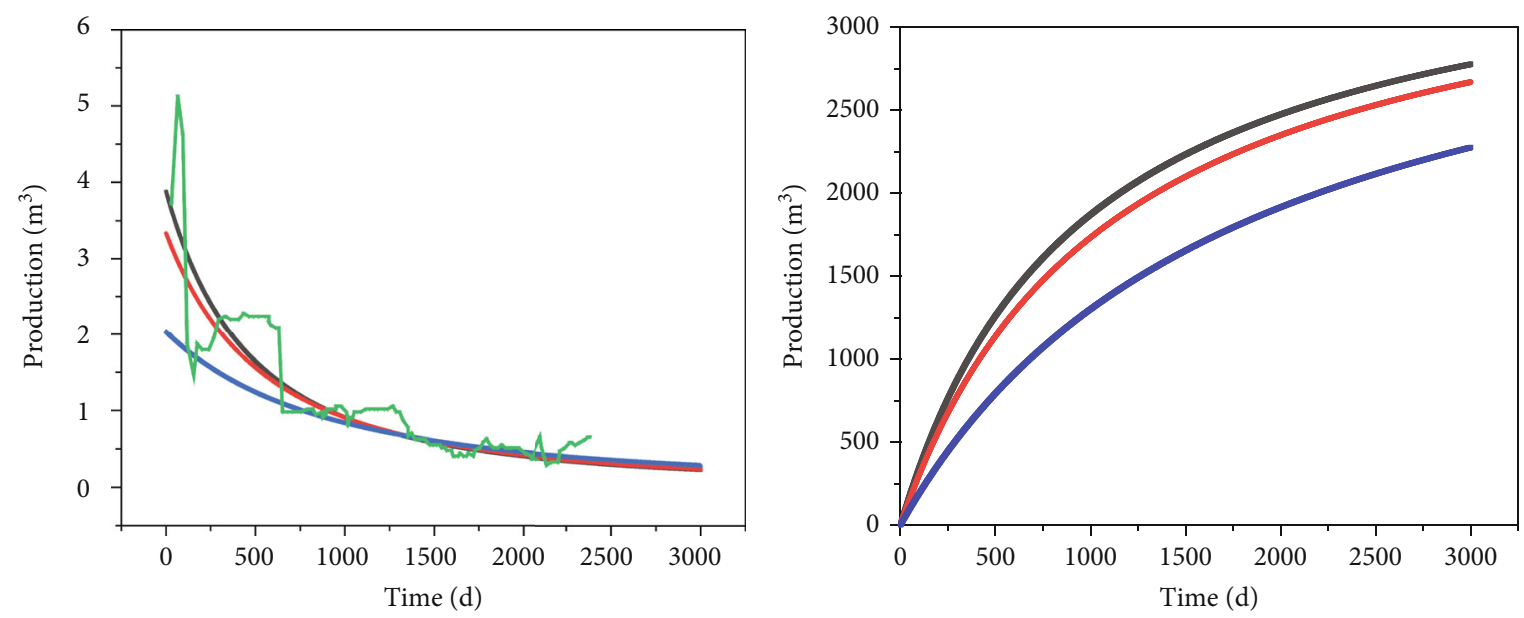

$\rightarrow$ The stress sensitivity coefficient is 0.005

- The stress sensitivity coefficient is 0.05

$\rightarrow$ The stress sensitivity coefficient is 0.1

$\rightarrow$ Actual production curve

FIGURE 14: Schematic diagram showing the effect of different stress sensitivity coefficients on the yield.

The integral of Equation (29) is

$S_{w}=1-S_{\mathrm{or}}-\left[\left(1-S_{w c}-S_{\mathrm{or}}\right)^{n_{o}}+\frac{n_{o}-1}{\left(1-S_{w c}-S_{\mathrm{or}}\right)^{n_{o}}} \frac{m K_{r o}\left(S_{w c}\right) B_{o}}{V_{p}} t\right]^{1 /\left(-n_{o}+1\right)}$.

After differentiation, we can obtain

$Q_{\mathrm{o}}=m K_{r o}\left(S_{w c}\right)\left[1+\frac{n_{o}-1}{1-S_{w c}-S_{\mathrm{or}}} \frac{m K_{r o}\left(S_{w c}\right) B_{o}}{V_{p}} t\right]^{n_{o} /\left(-n_{o}+1\right)}$.

The cumulative oil production can be obtained by integrating Equation (33):

$$
\begin{aligned}
N_{\mathrm{p}}= & \frac{V_{p}\left(1-S_{w c}-S_{\mathrm{or}}\right)}{B_{o}}-\frac{V_{p}\left(1-S_{w c}-S_{\mathrm{or}}\right)}{B_{o}} \\
& \cdot\left[1+\frac{n_{o}-1}{1-S_{w c}-S_{\mathrm{or}}} \frac{m K_{r o}\left(S_{w c}\right) B_{o}}{V_{p}} t\right]^{n_{o} /\left(-n_{o}+1\right)} .
\end{aligned}
$$

Therefore, the yield prediction model of the multistage seepage model for tight reservoirs is

$$
W_{p}=N_{p}+Q
$$

4.3. Model Results and Discussion. In this study, MATLAB (2018b) was used to program and calculate the calculation process. The influences of factors such as imbibition, the stress sensitivity, the threshold pressure gradient, and the Jamin effect on model's output were compared, and suggestions for field development were formulated. The basic model calculation parameters are presented in Table 2.
4.3.1. Consideration of the Impact of Imbibition on Production. Figure 13 shows the cumulative yield without considering the imbibition effect, the cumulative yield with considering the infiltration effect, and the cumulative yield only considering the infiltration effect in the secondary and tertiary pores. It can be seen from the diagram that the yield considering imbibition is significantly larger than that without considering imbibition. This shows that imbibition can replace the oil that is difficult to displace from the small pores into the microcracks and macropores, which can then be displaced to produce, increasing the yield. The yield considering the only imbibition is very small compared to the total yield, indicating that the oil production contribution of imbibition to the total yield is limited. The curved shape initially increases, and the cumulative yield remains unchanged after some time, indicating that imbibition plays a role during this period. This process involves gradually replacing the oil in the small pores. When the curve remains unchanged, the imbibition process has replaced the oil in the second and third pores.

4.3.2. Effect of Stress Sensitivity on the Yield. Figure 14 shows the daily oil production and the cumulative oil production for stress sensitivity coefficients of $0.005,0.05,0.1$, and 0.2 . In the figure, the trial calculation was conducted using data from Well Chang 7, and the results are compared with the field results. The error of the trial calculation results is small. It can be seen from the figure that as the stress sensitivity coefficient increases, the oil production constantly decreases. In addition, the decline in production during the early stage of mining is relatively fast, and the decline in the late stage is relatively slow, exhibiting a trend of high yield in the early stage and stable yield in the late stage. In early-stage mining oil production, the gap is relatively large, but the gap gradually narrows with time. This is because the greater the stress sensitivity coefficient is, the greater the damage rate of the reservoir permeability is. Based on the model calculation 

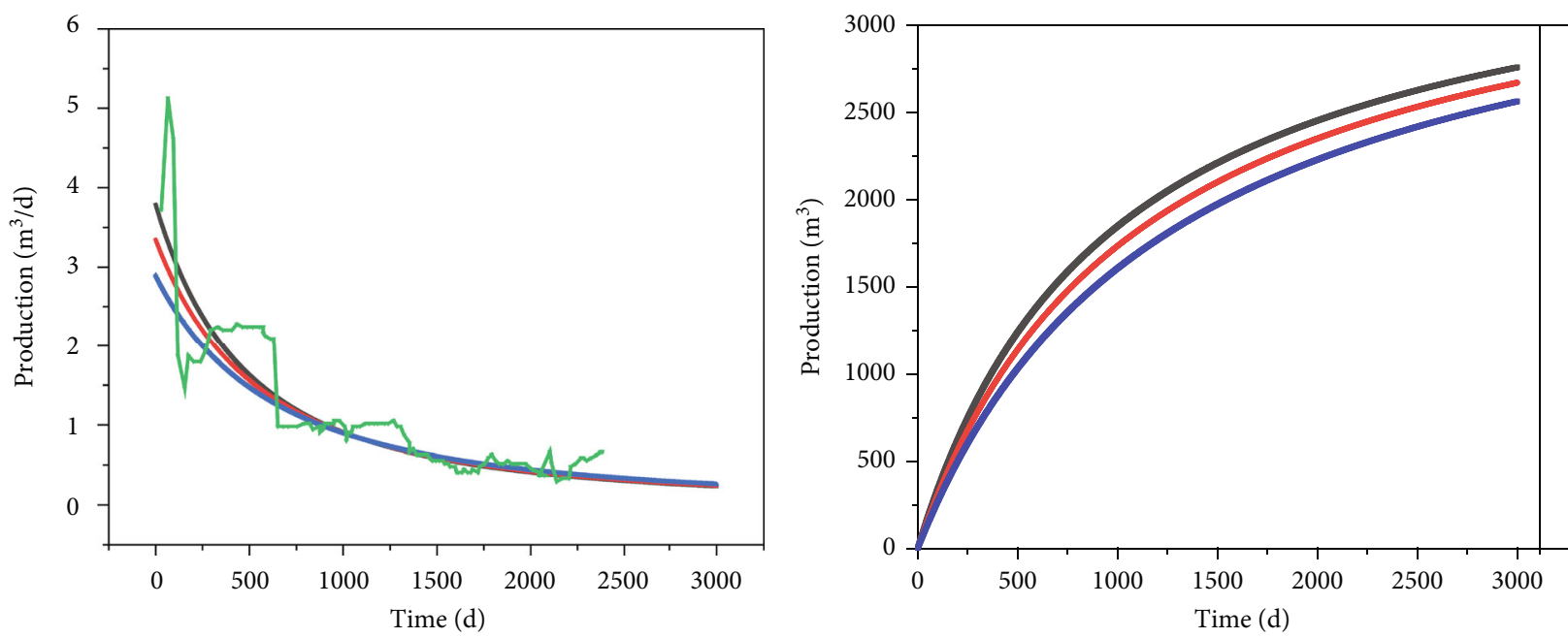

—- Threshold pressure gradient is $0.0023 \mathrm{MPa} / \mathrm{m}$

$\ldots$ Threshold pressure gradient is $0.0053 \mathrm{MPa} / \mathrm{m}$

— Threshold pressure gradient is $0.0083 \mathrm{MPa} / \mathrm{m}$

$\because$ Actual production curve

FIGURE 15: Diagram showing the effect of different threshold pressure gradients on the yield.
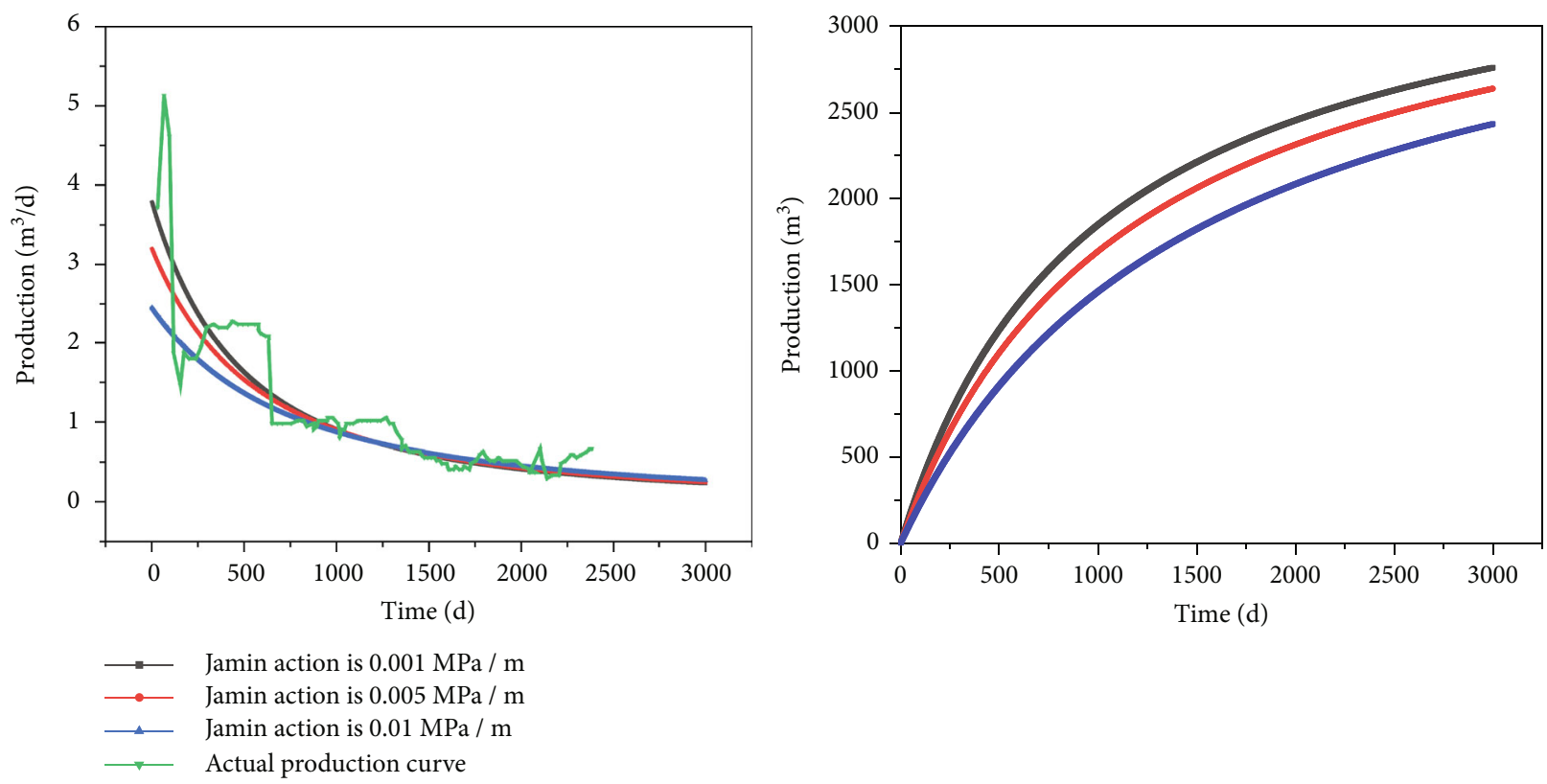

FIGURE 16: Diagram showing the effect of different scales of the Jamin effect on the yield.

results, increasing the stress sensitivity coefficient should be avoided to prevent a rapid decline in production.

\subsubsection{Effect of Threshold Pressure Gradient on the Yield.} Figure 15 shows the daily oil production and cumulative oil production for threshold pressure gradients of $0.0023 \mathrm{MPa} / \mathrm{m}, 0.0053 \mathrm{MPa} / \mathrm{m}$, and $0.0083 \mathrm{MPa} / \mathrm{m}$. In the figure, the trial calculations were conducted using data from Well Chang 7, and the results are compared with the field results. The error of the trial calculation results is small. It can be seen from the figure that as the threshold pressure gradient increases, the oil production continues to decline.
The production declines in the early stage of mining, while the decline in the late stage is slow, exhibiting a trend of high yield in the early stage and stable yield in the late stage. In early-stage mining oil production, the gap is relatively large, but the gap gradually narrows with time. This is because the effect of the threshold pressure gradient is equivalent to the increase in the seepage resistance, which reduces the effective production pressure difference, resulting in poor fluid flow. Therefore, the effect of the threshold pressure gradient cannot be ignored, and measures need to be taken to reduce the threshold pressure gradient and increase production. 
4.3.4. Effect of the Jamin Effect on the Yield. Figure 16 shows the daily oil production and cumulative oil production for Jamin effect values of $0.001 \mathrm{MPa} / \mathrm{m}, 0.005 \mathrm{MPa} / \mathrm{m}$, and $0.01 \mathrm{MPa} / \mathrm{m}$. In the figure, the trial calculations were conducted using data from Well Chang 7, and the results are compared with the field results. The error of the trial calculation results is small. It can be seen from the figure that as the Jamin effect increases, the oil production continues to decline. The production declines in the early stage of mining, and the decline in the late stage is slow, exhibiting a trend of high yield in the early stage and stable yield in the late stage. In early-stage mining oil production, the gap is relatively large, but the gap gradually narrows with time. This is because the Jamin effect on the two-phase flow mainly comes from the oil droplet displacement to the large pores by imbibition, which increases the two-phase interface. In the late stage of mining, owing to the gradual weakening of the imbibition, the two-phase interface decreases sharply, and the corresponding Jamin effect is weakened. Therefore, as the Jamin effect increases, production decreases. For tight reservoirs, the Jamin effect is stronger, and its influence is greater.

\section{Conclusions}

In this study, a conceptual model of multistage seepage in tight reservoirs was established, and a corresponding mathematical model was established based on the characteristics of the concept model to study the seepage law of tight reservoirs under multiple factors. Based on this, the seepage law of tight oil reservoirs containing microfractures was studied through two groups of online NMR experiments involving water flooding and gas flooding. The following conclusions were drawn based on the experiments and models.

(1) According to the seepage characteristics of tight reservoirs, a conceptual model of multistage seepage in tight reservoirs was proposed. This model mainly applies to the matrix seepage area that is not affected by fracturing cracks. This area is generally far away from the artificial cracks. In contrast to the seepage law of large cracks, the specific surface area in this region is large, and the viscosity is strong. In this model, the pores in the reservoir are divided into three grades according to their flow sizes: primary pores, secondary pores, and tertiary pores. The oilwater two-phase flow occurs in the primary pores, and the oil is displaced from the secondary and tertiary pores by imbibition to participate in the oilwater two-phase flow

(2) In the process of low permeability and tight reservoir development, the main seepage channels for oilwater two-phase flow are the microcracks, large pores, and throats in the reservoir. The size of the large pores is mainly concentrated in the micron and submicron range, and there is no two-phase flow in the small pores. During water flooding, the imbibition effect cannot be ignored, and the oil produc- tion can account for $5-11 \%$ of the initial oil content. The main reason for this is that the oil that cannot be displaced from the small pores is transferred to the large pores and microcracks via imbibition replacement to participate in the two-phase flow, and then, the oil is produced. Because the imbibition occurs under the action of capillary force, the higher the degree of core microcracks development, the more submicron pores connected by microcracks, resulting in oil in submicron pores transferring to microcracks. If only the two displacement processes before and after imbibition are considered, the change of oil content mainly occurs in micron pores, indicating that the two-phase flow of water flooding oil mainly occurs in larger pores, such as micron pores, and there is no two-phase flow in nanopores and micro-nanopores. In the laboratory, the effect of water flooding on oil recovery is high, and the recovery is nearly doubled. As the degree of microcrack development increases, the ultimate recovery initially increases and then decreases. During gas flooding, the effect of a stuffy well on recovery is low. The higher the degree of microcrack development, the lower the recovery

(3) In the multistage seepage model, the effects of suction, the stress sensitivity, the threshold pressure gradient, and the Jamin effect on model's yield are considered. In the model, imbibition no longer works after a while because the early imbibition has replaced the oil in the secondary and tertiary pores. When the stress sensitivity, the initial pressure gradient, and the Jamin effect are considered, the oil production will be reduced. As the parameter values increase, the oil production will continue to decline. The decline in production in the early stage of mining is relatively fast, and the decline in the late stage is relatively slow, exhibiting a trend of high yield in the early stage and stable yield in the late stage

\section{Data Availability}

The data used to support the findings of this study are available from the corresponding author upon request.

\section{Conflicts of Interest}

The authors declare that there are no conflicts of interest regarding the publication of this paper.

\section{Acknowledgments}

This work was supported by the CNPC Basic Advanced Reserve Technology (2021DJ2201) and the General Program of Chongqing Natural Science Foundation (No. cstc2020jcyjmsxmX0659). 


\section{References}

[1] B. Jia, J. S. Tsau, and R. Barati, "Role of molecular diffusion in heterogeneous, naturally fractured shale reservoirs during $\mathrm{CO}_{2}$ huff-_n_ - puff," Journal of Petroleum Science and Engineering, vol. 164, pp. 31-42, 2018.

[2] C. Zou, G. Zhang, Z. Yang et al., "Concepts, characteristics, potential and technology of unconventional hydrocarbons: on unconventional petroleum geology," Petroleum Exploration and Development, vol. 40, no. 4, pp. 413-428, 2013.

[3] C. Zou, R. K. Zhu, S. T. Wu et al., "Types, characteristics, genesis and prospects of conventional and unconventional hydrocarbon accumulations: taking tight oil and tight gas in China as an instance," Acta Petrolei Sinica, vol. 33, no. 2, pp. 173-187, 2012.

[4] O. G. Apaydin, E. Ozkan, and R. Raghavan, "Effect of discontinuous microfractures on ultratight matrix permeability of a dual-porosity medium," SPE Reservoir Evaluation \& Engineering, vol. 15, no. 4, pp. 473-485, 2012.

[5] P. Zhu, C. Y. Lin, H. Q. Ren, Z. Zhao, and H. Zhang, "Microfracture characteristics of tight sandstone reservoirs and its evaluation by capillary pressure curves: a case study of Permian sandstones in Ordos Basin, China," Journal of Natural Gas Science and Engineering, vol. 27, pp. 90-97, 2015.

[6] W. J. Shen, X. Z. Li, T. R. Ma, J. Cai, X. Lu, and S. Zhou, "High-pressure methane adsorption behavior on deep shales: experiments and modeling," Physics of Fluids, vol. 33, no. 6, article 063103, 2021.

[7] Y. Zhao, W. Wang, R. Guo et al., "Relation of heterogeneity and gas-bearing capacity of tight sandstone: a case study of the Upper Paleozoic tight gas sandstone reservoir in the southeast of the Ordos Basin," ACS Omega, vol. 24, no. 6, pp. 1571615726, 2021.

[8] X. Y. Kong, Advanced Mechanics of Fluids in Porous Media, University Of Science And Technology of China Press, Hefei, 1999.

[9] X. LI, D. LU, R. LUO et al., "Quantitative criteria for identifying main flow channels in complex porous media," Petroleum Exploration and Development, vol. 46, no. 5, pp. 998-1005, 2019.

[10] X. LI, R. LUO, Y. HU et al., "Main flow channel index in porous sand reservoirs and its application," Petroleum Exploration and Development, vol. 47, no. 5, pp. 10551061, 2020.

[11] F. J. Dong, Y. Cao, D. Z. Ren, and W. Sun, "Micro-fracture development impact factors analysis and its effects on well production of Hua-qing area Ordos Basin in China," International Journal of Oil, Gas and Coal Technology, vol. 21, no. 1, pp. 39-56, 2019.

[12] R. F. Sun, J. H. Hu, Y. Zhang, and Z. Li, "A semi-analytical model for investigating the productivity of fractured horizontal wells in tight oil reservoirs with micro-fractures," Journal of Petroleum Science and Engineering, vol. 186, p. 106781, 2020.

[13] X. Feng, J. Zeng, H. Zhan, Y. Zhang, J. Qiao, and S. Feng, "Influence of boundary layer on oil migration into tight reservoirs," Transport in Porous Media, vol. 137, no. 1, pp. 87-107, 2021.

[14] Z. D. Yang, Y. Wang, X. Y. Zhang et al., "Numerical simulation of a horizontal well with multi-stage oval hydraulic fractures in tight oil reservoir based on an embedded discrete fracture model," Frontiers in Energy Research, vol. 8, p. 310, 2020.
[15] Y. L. Su, Z. F. Li, S. Y. Zhan, D. Li, and G. Sheng, "Correction for capillary pressure influence on relative permeability by combining modified black oil model and Genetic Algorithm," Journal of Petroleum Science and Engineering, vol. 204, p. 108762, 2021.

[16] F. Mo, X. L. Peng, D. Devegowda et al., "Permeability jail for two-phase flow in tight sandstones: formulation, application and sensitivity studies," Journal of Petroleum Science and Engineering, vol. 184, p. 106583, 2020.

[17] J. H. Hu, R. Sun, and Y. Zhang, "Investigating the horizontal well performance under the combination of micro-fractures and dynamic capillary pressure in tight oil reservoirs," Fuel, vol. 269, p. 117375, 2020.

[18] L. Li, Y. M. Hao, Y. Lv et al., "Experimental investigation on low-velocity seepage characteristics and influencing factors in a shale oil reservoir," Journal of Petroleum Science and Engineering, vol. 195, p. 107732, 2020.

[19] L. Yang, S. Wang, Z. G. Tao, R. Leng, and J. Yang, "The characteristics of oil migration due to water imbibition in tight oil reservoirs," Energies, vol. 12, no. 21, p. 4199, 2019.

[20] X. GU, C. PU, H. HUANG et al., "Micro-influencing mechanism of permeability on spontaneous imbibition recovery for tight sandstone reservoirs," Petroleum Exploration and Development, vol. 44, no. 6, pp. 1003-1009, 2017.

[21] Z. K. Wu, X. Z. Li, H. M. Xiao et al., "The establishment and evaluation method of artificial microcracks in rocks," Energies, vol. 14, no. 10, p. 2780, 2021.

[22] Y. L. Chen, L. H. Zhang, and J. C. Li, "Study of pore structure of gas shale with low-field NMR: examples from the Longmaxi formation, Southern Sichuan basin, China," in In SPE Asia Pacific Unconventional Resources Conference and Exhibition, Brisbane, Australia, November 2015.

[23] X. W. Wang, Z. M. Yang, H. B. Li, and H. K. Guo, "Experimental study on pore structure of low permeability core with NMR spectra," Journal of Southwest Petroleum University (Science \& Technology Edition), vol. 32, no. 2, pp. 69-72, 2010.

[24] F. P. Lai, Z. P. Li, Q. Wei, T. Zhang, and Q. Zhao, "Experimental investigation of spontaneous imbibition in a tight reservoir with nuclear magnetic resonance testing," Energy \& Fuels, vol. 30, no. 11, pp. 8932-8940, 2016.

[25] W. Lin, X. Li, Z. Yang et al., "A new improved threshold segmentation method for scanning images of reservoir rocks considering pore fractal characteristics," Fractals, vol. 26, no. 2, article 1840003, 2018.

[26] F. L. Zhao, P. C. Liu, S. Y. Hao, X. Qiu, C. Shan, and Y. Zhou, "A new dynamic capillary-number-recovery evaluation method for tight gas reservoirs," Journal of Petroleum Science and Engineering, vol. 204, p. 108730, 2021.

[27] M. Hasan, M. Eliebid, M. Mahmoud, S. Elkatatny, and R. Shawabkeh, "Enhanced gas recovery (EGR) methods and production enhancement techniques for shale \& tight gas reservoirs," in SPE Kingdom of Saudi Arabia Annual Technical Symposium and Exhibition, OnePetro, 2017.

[28] Q. Hou, J. Sun, J. Jing et al., "Numerical simulation study on fracture parameter optimization in developing low-permeability anisotropic reservoirs," Geofluids, vol. 2018, 9 pages, 2018.

[29] Z. Rahim, A. Al-Kanaan, H. Al-Anazi, R. Kayumov, and Z. Al-Jalal, "Impact of multistage fracturing on tight gas recovery from Saudi Arabian high pressure high temperature carbonate reservoirs," in SPE Asia Pacific Unconventional Resources Conference and Exhibition, OnePetro, 2015. 
[30] G. T. Mao, F. P. Lai, Z. P. Li, H. Wei, and A. Zhou, "Characteristics of pore structure of tight gas reservoir and its influence on fluid distribution during fracturing," Journal of Petroleum Science and Engineering, vol. 193, p. 107360, 2020.

[31] W. Lin, S. C. Xiong, Y. Liu, Y. He, S. Chu, and S. Liu, "Spontaneous imbibition in tight porous media with different wettability: pore-scale simulation," Physics of Fluids, vol. 33, no. 3, article 032013, 2021.

[32] H. Cheng and F. Y. Wang, "Mathematical model of the spontaneous imbibition of water into oil-saturated fractured porous media with gravity," Chemical Engineering Science, vol. 231, no. $15,2021$.

[33] Q. G. Tan, Y. L. Kang, L. J. You, C. Xu, X. Zhang, and Z. Xie, "Stress-sensitivity mechanisms and its controlling factors of saline-lacustrine fractured tight carbonate reservoir," Journal of Natural Gas Science and Engineering, vol. 88, p. 103864, 2021. 